Case Report

\title{
Long-Term Outcomes of Radial Keratotomy, Laser In Situ Keratomileusis, and Astigmatic Keratotomy Performed Consecutively over a Period of 21 Years
}

\author{
Priyanka Chhadva, ${ }^{1}$ Florence Cabot, ${ }^{1,2}$ Anat Galor, ${ }^{1,3}$ and Sonia H. Yoo ${ }^{1,2}$ \\ ${ }^{1}$ University of Miami Miller School of Medicine, Bascom Palmer Eye Institute, Miami, FL 33136, USA \\ ${ }^{2}$ Ophthalmic Biophysics Center, McKnight Vision Center, Miami, FL 33136, USA \\ ${ }^{3}$ Miami Veterans Administration Medical Center, Miami, FL 33125, USA \\ Correspondence should be addressed to Sonia H. Yoo; syoo@med.miami.edu
}

Received 22 January 2015; Revised 24 February 2015; Accepted 25 February 2015

Academic Editor: Giacomo Savini

Copyright (C) 2015 Priyanka Chhadva et al. This is an open access article distributed under the Creative Commons Attribution License, which permits unrestricted use, distribution, and reproduction in any medium, provided the original work is properly cited.

Purpose. To describe a case of 3 refractive procedures performed in one eye over 2 decades. Methods. Case report. Results. A 41year-old patient presented for refractive surgery evaluation. His ocular history includes bilateral radial keratotomy performed 21 years ago for moderate myopia: spherical equivalence of $-4.25 \mathrm{D}$ bilaterally. Postoperative uncorrected visual acuity (UCVA) was 20/30; however, over time he developed a hyperopic shift and UCVA decreased to 20/40 in the right eye. Thus, laser-assisted in situ keratomileusis (LASIK) was performed at an outside institution 6.5 years later, and the patient had initial improvement of UCVA to $20 / 25$. Due to a change in refractive error, the patient underwent uneventful astigmatic keratotomy 13 years after LASIK in the right eye, and 1.5 years after surgery best-corrected visual acuity was $20 / 25$ with manifest refraction of $-1.00+5.50 \times 134^{\circ}$. Conclusion . We report the outcomes and natural refractive progression in a patient who underwent three corneal refractive procedures over two decades. This case underlines the difficulties of long-term management of post-RK hyperopia and astigmatism.

\section{Introduction}

Radial keratotomy (RK), first performed in the United States in 1978, was viewed as an effective procedure with excellent immediate postoperative outcomes [1]. However, it has been well documented that the radial incisions made in the cornea cause gradual hyperopic shifts. The causes of such hyperopic shift after RK are not well known, but these shifts have been speculated to be due to peripheral corneal bulging and compensatory central corneal flattening [2]. Such incisional alterations cause biomechanical instability of the cornea, leading to unpredictable long-term results [3-5]. Laserassisted in situ keratomileusis (LASIK) has been used in these cases, but results are suboptimal in patients with hyperopic astigmatism and long-term results are not as stable or as predictable as in naïve corneas [6-8]. Astigmatic keratotomy (AK) has been described in patients with naïve corneas and with postpenetrating keratoplasty to correct astigmatism, but it has not been discussed after RK to our knowledge. We describe outcomes after LASIK and AK were performed sequentially in the same eye to correct post-RK hyperopia and astigmatism to highlight the difficulties in managing refractive status in such patients.

\section{Case Presentation}

A 41-year-old Hispanic man who wore soft contact lenses for 15 years presented to Bascom Palmer Eye Institute for refractive surgery evaluation 21 years ago. In the right eye, uncorrected visual acuity (UCVA) was 6/200 and manifest refraction (MR) was -4.5 sphere with corrected distance visual acuity (BCVA) 20/20. Preoperative topography showed a low amount of with-the-rule astigmatism (corneal cylinder $(C C)=0.40$ D; Figure 1(a)). In the left eye, initial UCVA was $7 / 200$ and MR was -4.5 sphere with BCVA 20/20. 


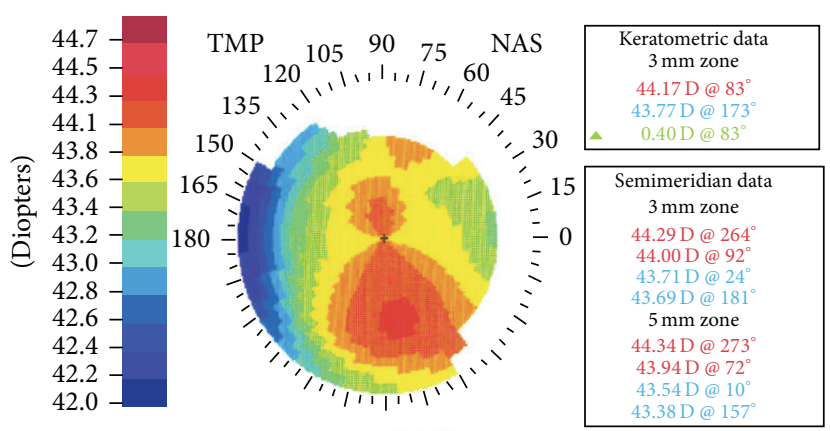

(a)
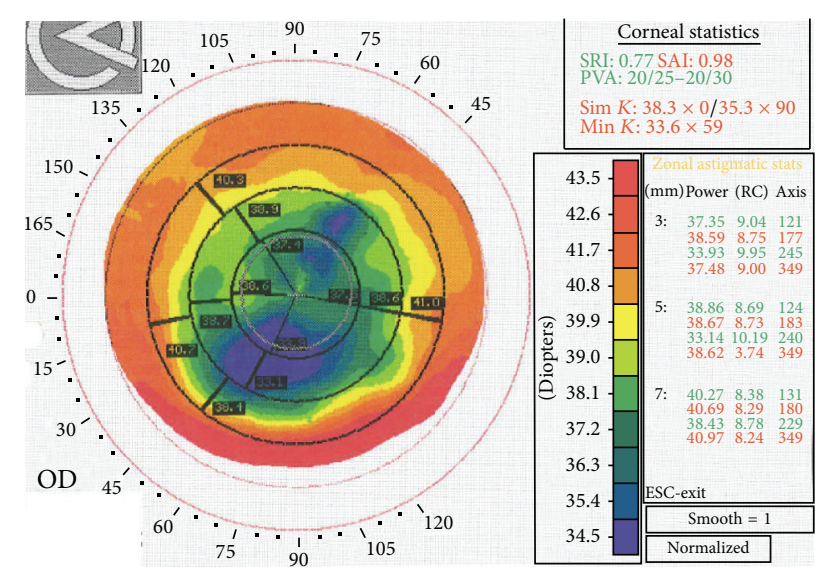

(c)

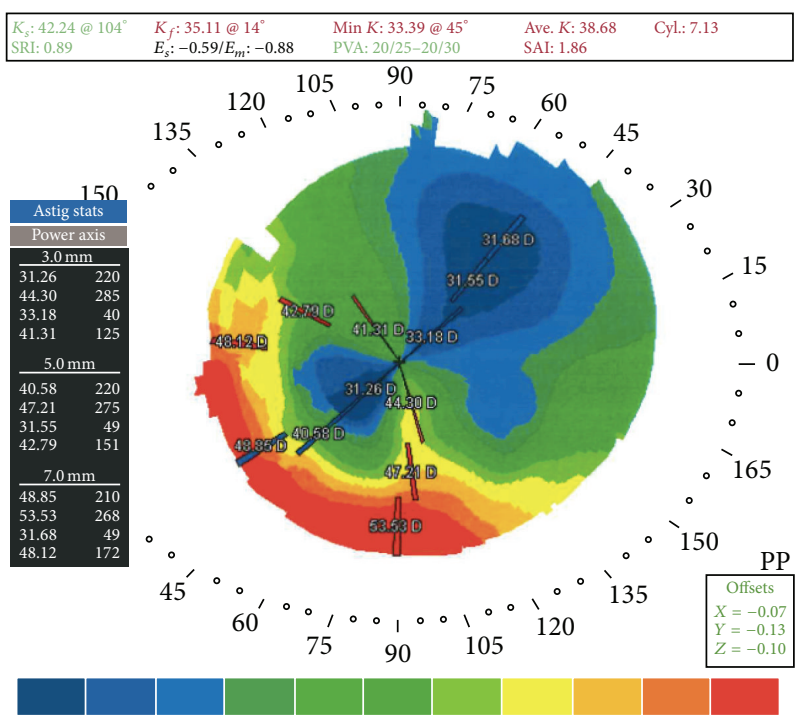

$\begin{array}{lllllllllll}31.9 & 33.8 & 35.7 & 37.6 & 39.5 & 41.4 & 43.3 & 45.2 & 47.1 & 49.0 & 50.9\end{array}$

(e)

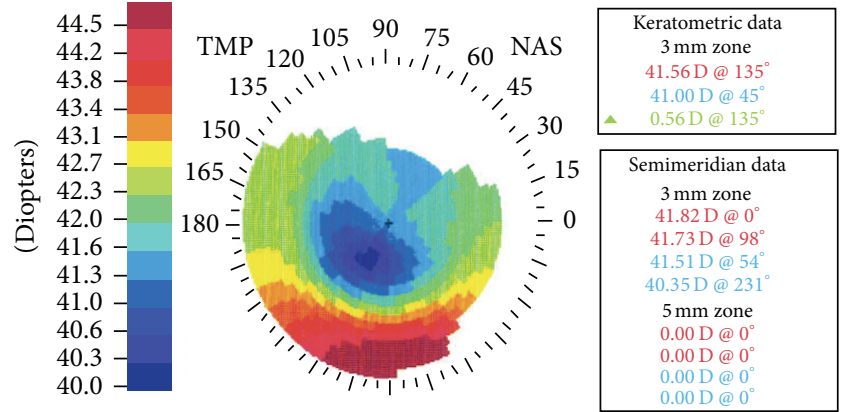

(b)
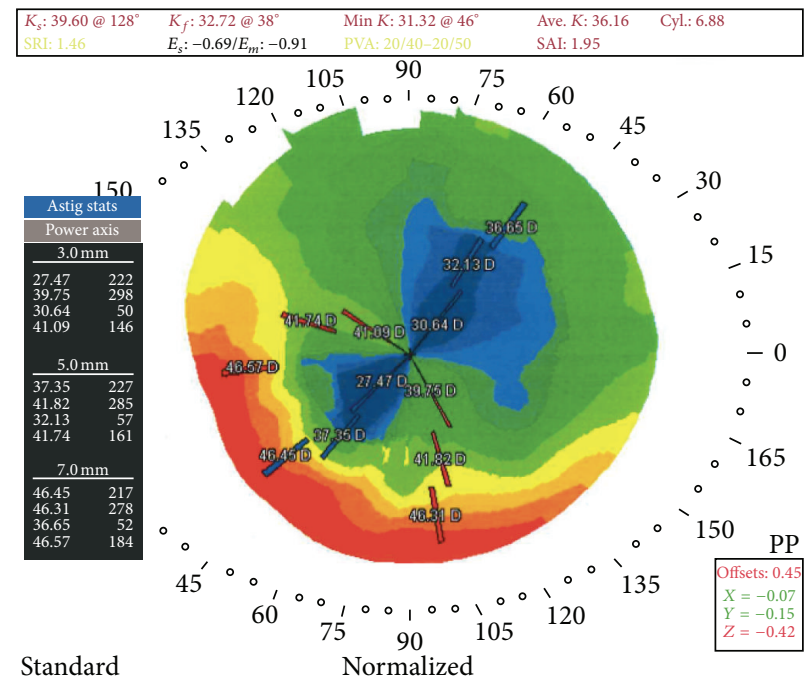

Standard

Normalized

$\begin{array}{lllllllllll}31.1 & 32.8 & 34.5 & 36.2 & 37.9 & 39.6 & 41.3 & 43.0 & 44.7 & 46.4 & 48.1\end{array}$

(Diopters)

(d)

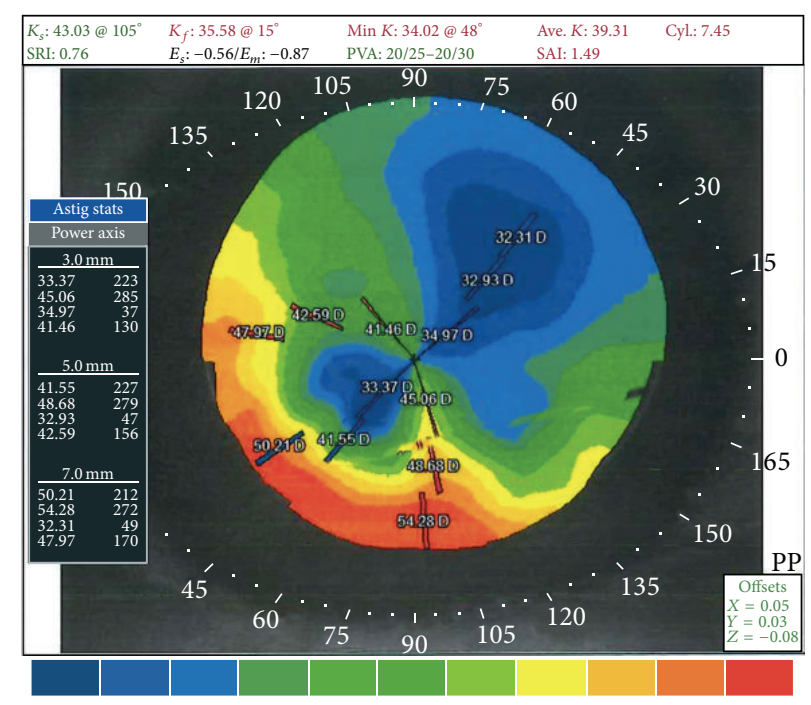

$\begin{array}{lllllllllll}33.7 & 35.5 & 37.3 & 39.1 & 40.9 & 42.7 & 44.5 & 46.3 & 48.1 & 49.9 & 51.7\end{array}$

(f)

FIGURE 1: Corneal Topography. Progression of corneal topography measured in patient's right eye: (a) preoperative topography (before radial keratotomy $[\mathrm{RK}]$ ), (b) postoperative month 1 after RK, (c) postoperative month 5 after LASIK, (d) postoperative year 6 after LASIK, (e) postoperative month 4 after astigmatic keratotomy (AK), and (f) postoperative year 1.5 after AK. 


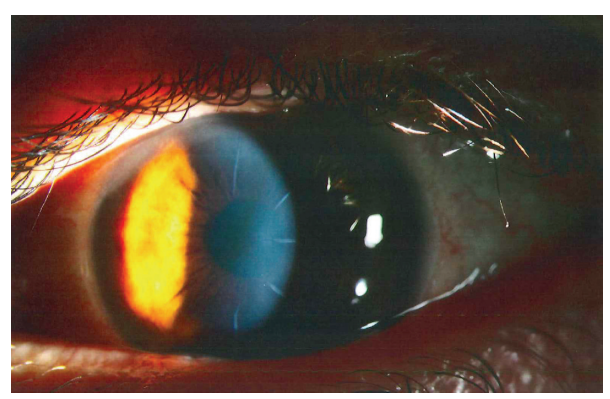

(a)

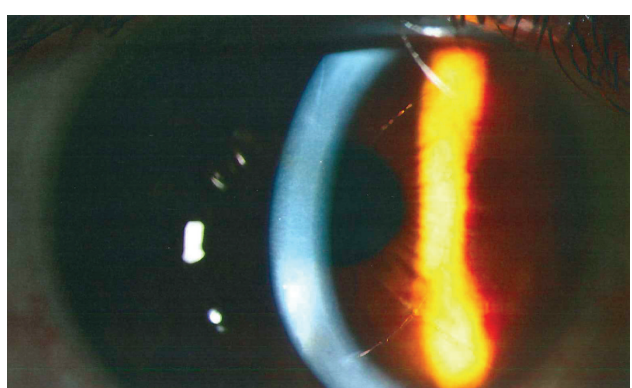

(b)

FIGURE 2: Slit Lamp Photography. Patient's right eye detailing: (a) radial keratotomy incisions and (b) astigmatic keratotomy incision. Even though the patient had LASIK, it is difficult to appreciate the LASIK flap in these photos.

Preoperative topography showed a low amount of with-therule astigmatism $(C C=0.73 \mathrm{D})$. To correct this patient's refractive error, RK was performed bilaterally.

For RK, ultrasound pachymetry measured a corneal thickness of $554 \mu \mathrm{m}$ at a position $1.5 \mathrm{~mm}$ temporal to the center of the cornea. The diamond blade was set to $544 \mu \mathrm{m}$. With the diamond knife, 8 centripetal manual incisions were created in a Russian-order fashion [9], leaving a $4 \mathrm{~mm}$ optic zone (Figure 2(a)). On postoperative day (POD) 1 , the patient had UCVA of 20/30 and BCVA of 20/25 in the right eye. On postoperative month (POM) 1, UCVA was stable (Figure 1(b)). Two years postoperatively, UCVA was 20/20, but the patient complained of increasing ghost images, haloes, and double vision. Over 6 years, the patient developed a hyperopic shift in the right eye (UCVA 20/40; MR +1.25 sphere with BCVA 20/25; CC = $1.50 \mathrm{D}$ ). However, in the left eye, visual acuity remained stable and clear, without hyperopic shift or astigmatism (UCVA 20/20; MR $-0.25+$ $0.25 \times 65^{\circ}$ with BCVA 20/20; CC $\left.=0.87 \mathrm{D}\right)$.

To address the hyperopic shift in the right eye, LASIK was performed at an outside institution 6.5 years after the RK procedure. A $130 \mu \mathrm{m}$ flap was created with microkeratome and excimer ablation was performed with VisX Star (Abbott Medical Optics, Santa Ana, CA, USA). On POD-4, UCVA was $20 / 25$ and MR was +0.75 sphere with BCVA 20/20. Five months after LASIK, UCVA was $20 / 30$ and MR was +0.75 sphere with BCVA 20/20, but the patient complained of haloes and double vision. Three and a half years after LASIK and according to medical records, the patient presented with worsening VA (UCVA 20/50; MR of $+1.25+2.75 \times 119^{\circ}$ with BCVA 20/20), which continued to deteriorate over the next 3 years (UCVA 20/400; MR -1.50 + 5.50 $\times 152^{\circ}$ with BCVA 20/20; topography Figures 1(c) and 1(d)). Seven years later, the change in BCVA and refractive error was mild (UCVA 20/300; MR $-2.25+6.50 \times 135^{\circ}$ with BCVA 20/25).

Thirteen years after his LASIK procedure, the patient returned to our institution complaining of decreased visual acuity. He tried contact lenses but proved intolerant with poor contact lens hygiene and insisted on being less dependent upon glasses; therefore an additional refractive procedure was considered to reduce astigmatism as a last option before a more invasive procedure (such as corneal transplant) would be considered. In order to correct this residual astigmatism,
femto-AK was performed using the IntraLase $150 \mathrm{kHz}$ femtosecond laser (Abbott Medical Optics, Santa Ana, CA, USA). Two arcuate incisions were made $\left(135^{\circ}\right.$ and $\left.315^{\circ}\right)$, each $70^{\circ}$ in length, at a depth of $412 \mu \mathrm{m}$ (Figure 2(b)). On POD-1, UCVA was 20/25 and MR was plano +0.50 × $137^{\circ}$ with BCVA 20/25. On POM-4, BCVA was 20/25 and increased cylinder was noted $\left(\mathrm{MR}-1.00+6.00 \times 128^{\circ}, \mathrm{CC}=7.13 \mathrm{D}\right.$, Figure $\left.1(\mathrm{e})\right)$. As such, the incisions were slightly opened at the slit lamp using a 30 -gauge needle. A year and a half later, UCVA was 20/50 and astigmatism was stable $\left(\mathrm{MR}-1.00+5.50 \times 134^{\circ}\right.$ with BCVA 20/20; Figure 1(f)).

On the other hand, in the left eye, although the patient developed a hyperopic shift with mild increasing astigmatism, he did not undergo any further refractive procedures and was comfortable wearing rigid gas permeable contact lenses in this eye (UCVA 20/50, MR +4.25 + $1.75 \times 50^{\circ}$ with BCVA 20/40; $\mathrm{CC}=1.76$ ).

\section{Discussion}

This case demonstrates the complexity of managing post-RK refractive outcomes. Visual disturbances, hyperopia, and astigmatism are well documented in post-RK patients. Visual dissatisfaction with RK has many etiologies, including corneal scarring, irregular astigmatism, hyperopic shift, and increasing width of radial incisions over time with resultant visual fluctuations $[3,4,7]$. As commonly seen, our patient developed hyperopic shift and astigmatism after RK in both eyes. To improve his visual acuity, LASIK and AK were performed in the right eye, 6.5 and 13 years later, respectively.

Results of LASIK to correct post-RK residual refractive error have been mixed: some studies showed relatively good outcomes, whereas others demonstrated poor outcomes and increased complication rates. For example, a study by Lipshitz et al. (12 eyes, $80 \%$ ) and Francesconi et al. (55 eyes, 80\%) demonstrated that post-RK eyes had refractive error within \pm 1.00 D of emmetropia 7 months after LASIK $[6,8]$. However, recurrent epithelial ingrowth leading to irregular astigmatism and loss of best-corrected vision have been reported [10]. Moreover, LASIK after RK proves to be more challenging than LASIK after other refractive procedures due to the fact that LASIK incision after RK must cut through the RK incisions. Therefore, the risk of flap and incision related 
complications are higher in these patients [11]. PRK is a surface ablation technique that avoids the creation of flaps and thus all flap-related complications. Hence, PRK is our current preferred technique in post-RK eyes, even though the associated risks include postoperative regression, haze, and unpredictable visual outcomes [12, 13]. Furthermore, such procedures (LASIK and PRK) are less predictable with poorer outcomes in corneas with irregular astigmatism, as the algorithms that are used to design treatment are meant for corneas with regular astigmatism. A better option for our patient might have been topography-guided surface treatment due to the irregular pattern of his astigmatism; however such techniques are not FDA-approved in the United States.

While $\mathrm{AK}$ is a good procedure to treat higher levels of astigmatism, to our knowledge, no cases have previously discussed this technique in the setting of post-RK-post-LASIK astigmatism. In our patient, astigmatism initially improved but these preliminary results were not stable and the patient had regression to his original degree of astigmatism. An option for post-RK visual changes or corneal ectasia includes corneal collagen cross-linking, which restores corneal stability. A case report by Mazzotta et al. reported CXL performed 10 years after RK due to corneal ectasia and hyperopic shift and at 1-year follow-up UCVA improved from 20/100 to 20/30 Snellen lines [14]. Another study by Elbaz et al. reported 9 eyes that underwent post-RK CXL due to worsening visual acuity; however the resulting 1 year follow-up UCVA was not statistically significantly different $(20 / 160$ to $20 / 80, P=0.3)$ [15]. However, long-term prospective studies are needed to validate this method.

To conclude, this case reinforces the difficulties in the long-term management of post-RK hyperopia and astigmatism. While not perfect, LASIK and AK provided visual rehabilitation in this patient, who had poor contact lens hygiene and wished to be less dependent upon glasses. Although topographically the outcome was not ideal, the patient was happy with his uncorrected visual outcome and was able to function in his daily activities without contact lenses after the AK procedure. However, the limitations of each procedure need to be stressed during the preoperative evaluation and realistic visual expectations need to be emphasized in these difficult cases.

\section{Disclosure}

Dr. Sonia H. Yoo is a consultant for Abbott Medical Optics (AMO, Santa Ana, CA, USA). None of the authors have financial or proprietary interests in the methods or materials described in this paper.

\section{Conflict of Interests}

The authors declare that there is no conflict of interests regarding the publication of this paper.

\section{Acknowledgments}

Dr. Anat Galor is supported by the Department of Veterans Affairs, Veterans Health Administration, Office of Research and Development, Clinical Sciences Research and Development's Career Development Award CDA-2-024-10S (Dr. Anat Galor), NIH Center Core Grant P30EY014801, and Research to Prevent Blindness Unrestricted Grant, Department of Defense (DOD Grant no. W81XWH-09-1-0675 and Grant no. W81XWH-13-1-0048 ONOVA) (institutional).

\section{References}

[1] M. Wang, "History of refractive surgery," in LASIK Vision Correction: The Exciting New Laser Eye Surgery, chapter 3, Med World Publishing, Provo, Utah, USA, 2000, http://drmingwang .com/book.html.

[2] K. D. Hanna, F. E. Jouve, and G. O. Waring III, "Preliminary computer simulation of the effects of radial keratotomy," Archives of Ophthalmology, vol. 107, no. 6, pp. 911-918, 1989.

[3] G. O. Waring III, M. J. Lynn, and P. J. McDonnell, "Results of the prospective evaluation of radial keratotomy (PERK) study 10 years after surgery," Archives of Ophthalmology, vol. 112, no. 10, pp. 1298-1308, 1994.

[4] G. O. Waring III, M. J. Lynn, W. Culbertson et al., “Threeyear results of the prospective evaluation of radial keratotomy (PERK) study," Ophthalmology, vol. 94, no. 10, pp. 1339-1354, 1987.

[5] M. R. Deitz, D. R. Sanders, M. G. Raanan, and M. DeLuca, "Long-term (5- to 12-year) follow-up of metal-blade radial keratotomy procedures," Archives of Ophthalmology, vol. 112, no. 5, pp. 614-620, 1994.

[6] I. Lipshitz, O. Man, G. Shemesh, M. Lazar, and A. Loewenstein, "Laser in situ keratomileusis to correct hyperopic shift after radial keratotomy," Journal of Cataract \& Refractive Surgery, vol. 27, no. 2, pp. 273-276, 2001.

[7] J. J. Rowsey and H. D. Balyeat, "Preliminary results and complications of radial keratotomy," The American Journal of Ophthalmology, vol. 93, no. 4, pp. 437-455, 1982.

[8] C. M. Francesconi, R. A. M. Nosé, and W. Nosé, "Hyperopic laser-assisted in situ keratomileusis for radial keratotomyinduced hyperopia," Ophthalmology, vol. 109, no. 3, pp. 602-605, 2002.

[9] J. C. Casebeer and C. A. Rae, "Keratorefractive diamond blade and surgical method," Google Patents, 1993.

[10] A. S. Forseto, R. A. M. Nosé, C. M. Francesconi, and W. Nosé, "Laser in situ keratomileusis for undercorrection after radial keratotomy," Journal of Refractive Surgery, vol. 15, no. 4, pp. 424428, 1999.

[11] L. W. Peacock, S. G. Slade, J. Martiz, A. Chuang, and R. W. Yee, "Ocular integrity after refractive procedures," Ophthalmology, vol. 104, no. 7, pp. 1079-1083, 1997.

[12] H. Joyal, J. Grégoire, and A. Faucher, "Photorefractive keratectomy to correct hyperopic shift after radial keratotomy," Journal of Cataract and Refractive Surgery, vol. 29, no. 8, pp. 1502-1506, 2003.

[13] I. C. Kuo, S. M. Lee, and D. G. Hwang, "Late-onset corneal haze and myopic regression after photorefractive keratectomy (PRK)," Cornea, vol. 23, no. 4, pp. 350-355, 2004.

[14] C. Mazzotta, S. Baiocchi, R. Denaro, G. M. Tosi, and T. Caporossi, "Corneal collagen cross-linking to stop corneal ectasia exacerbated by radial keratotomy," Cornea, vol. 30, no. 2, pp. 225-228, 2011.

[15] U. Elbaz, S. N. Yeung, S. Ziai et al., "Collagen crosslinking after radial keratotomy," Cornea, vol. 33, no. 2, pp. 131-136, 2014. 


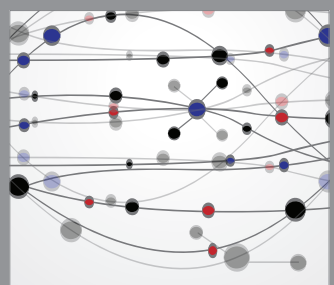

The Scientific World Journal
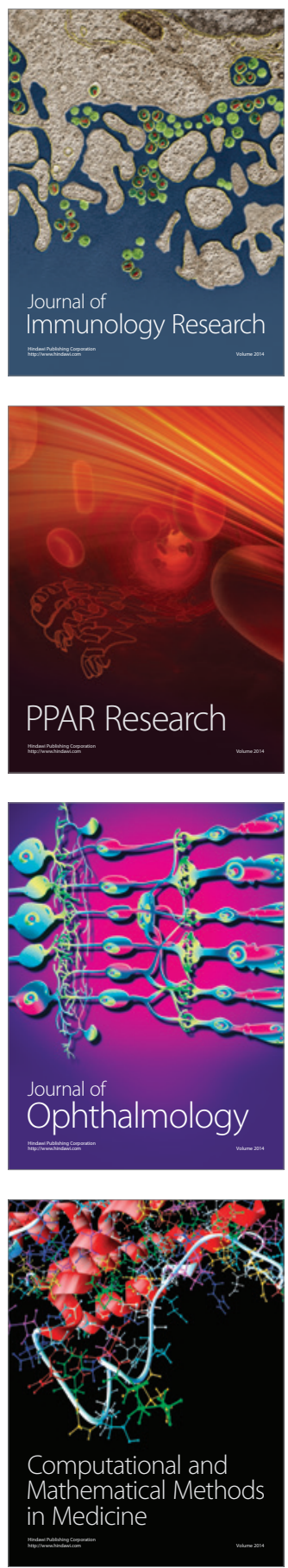

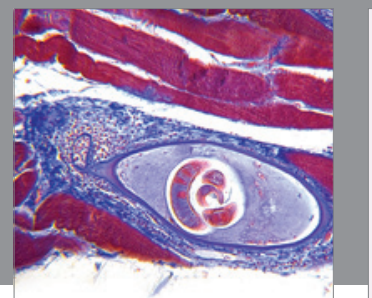

Gastroenterology

Research and Practice
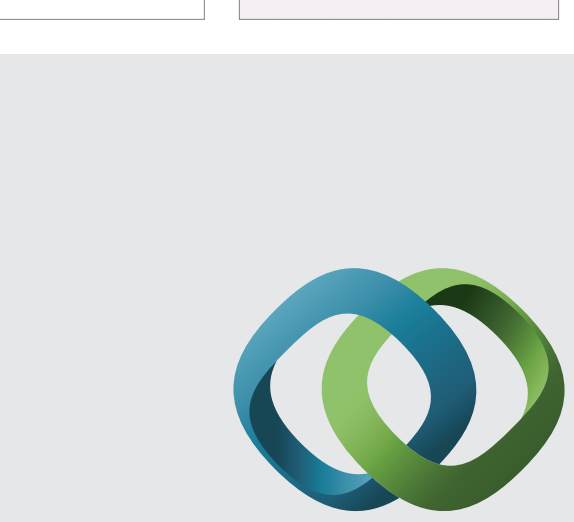

\section{Hindawi}

Submit your manuscripts at

http://www.hindawi.com
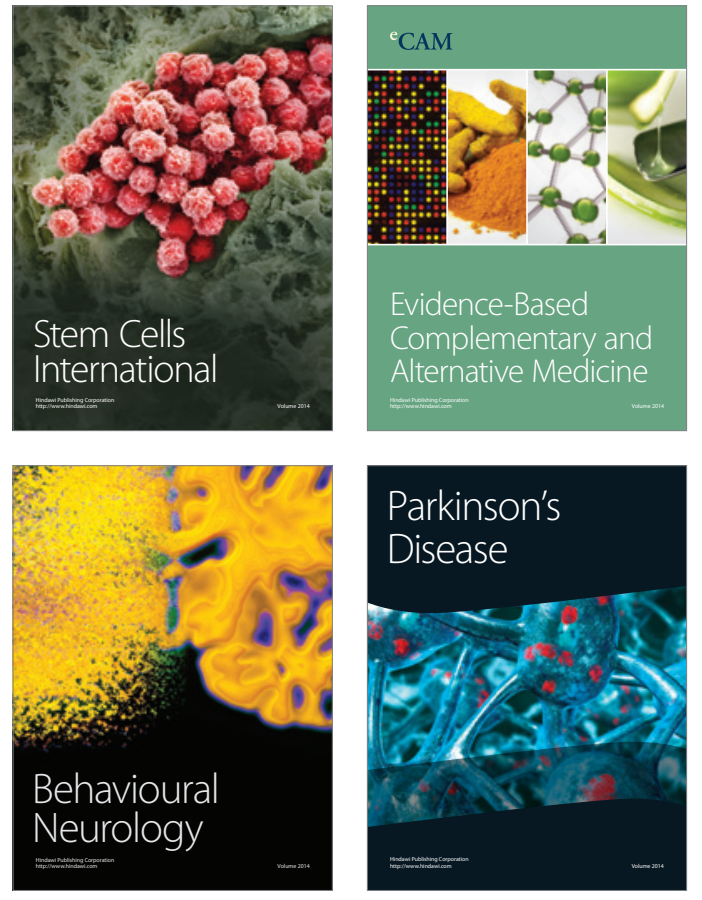
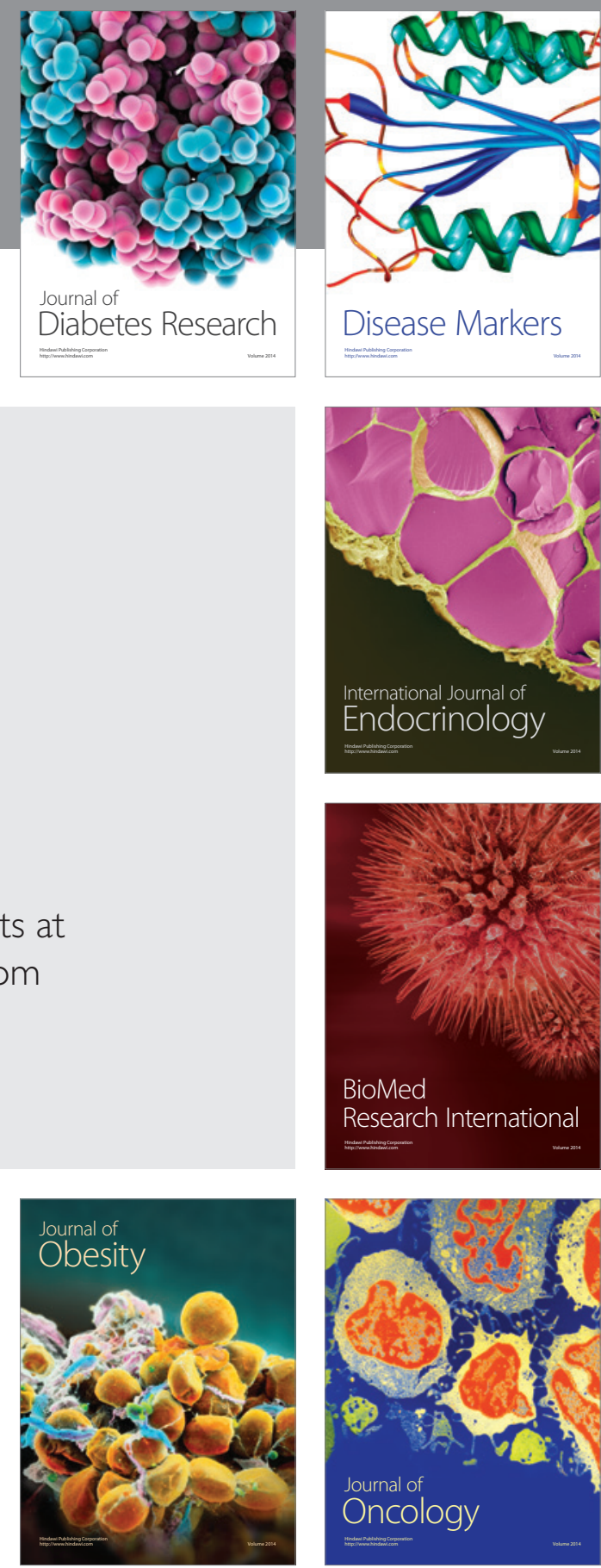

Disease Markers
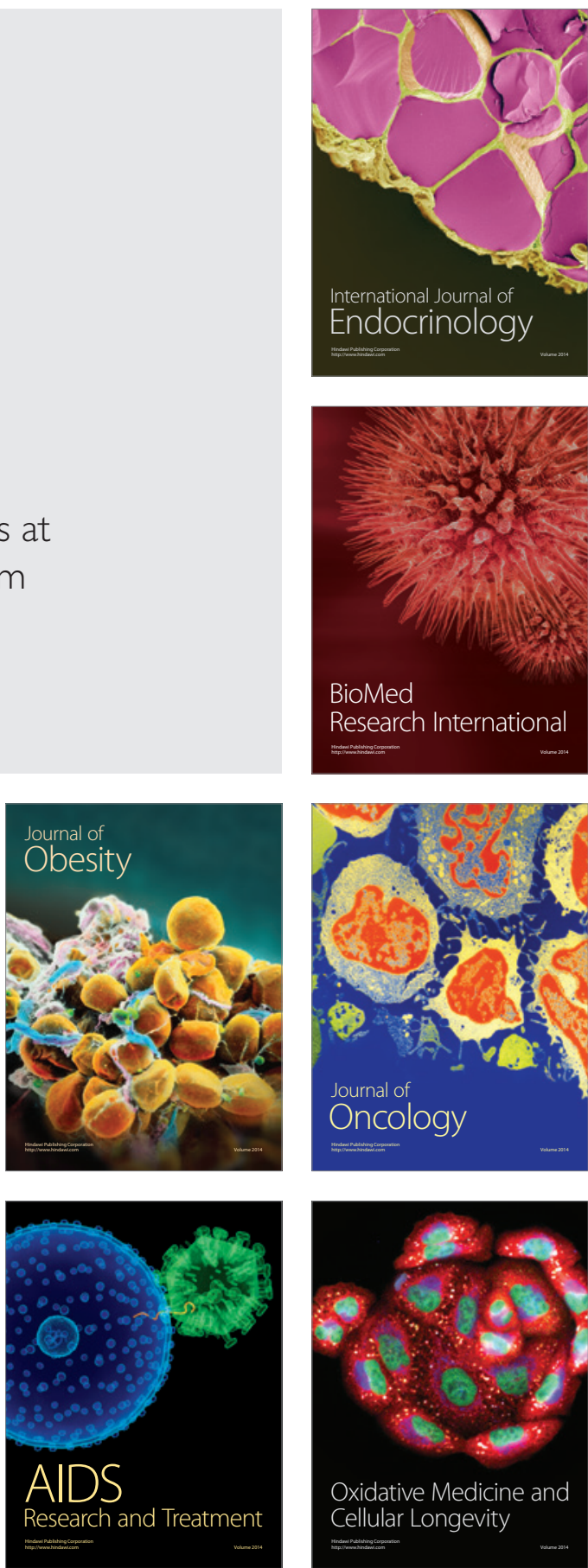